ABDI: Jurnal Pengabdian dan Pemberdayaan Masyarakat ISSN: 2656-369X (Print), 2684-8570 (Online)

Volume 3 No. 1, Juni 2021

http://abdi.ppj.unp.ac.id/index.php/abdi

Email: abdi@ppj.unp.ac.id

DOI: https://doi.org/10.24036/abdi.v3il.99

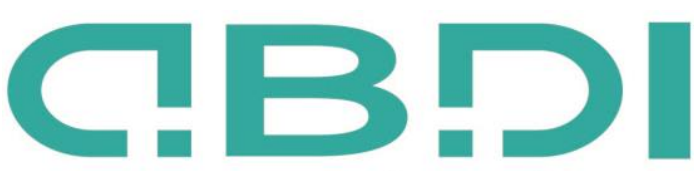

ABDI: JURNAL PENGABDIAN DAN PEMBERDAYAAN MASYARAKAT

\title{
Pelatihan Penerapan Hypnoparenting dalam Pengasuhan Anak Usia Dini
}

\author{
Sirjon Sirjon ${ }^{1}$, Endang Sri Mulyanie ${ }^{2}$, Andrianus Krobo ${ }^{3}$, Yansen Alberth Reba ${ }^{4}$ \\ ${ }^{1,2,3,4}$ Fakultas Keguruan dan Ilmu Pendidikan, Universitas Cenderawasih
}

E-mail: sirjonmamasa@gmail.com, endang.srimulyani952@gmail.com, krobozon@gmail.com, yansenreba070189@gmail.com

\begin{abstract}
Abstrak
Pola pengasuhan yang tepat dari orang tua, akan memberikan pengaruh signifikan terhadap perkembangan anak di masa yang akan datang. Kegiatan pengabdian ini berjudul Pelatihan Penerapan hypnoparenting dalam Pengasuhan Anak Usia Dini. Kegiatan ini dilaksankan di Koya Barat, Kotamadya Jayapura, Provinsi Papua. Tujuan kegiatan ini adalah untuk meningkatkan pemahaman dan kemampuan orang tua anak tentang konsep dan penerapan hypnoparenting dalam pengasuhan anak usia dini. Metode yang digunakan dalam kegiatan ini adalah training, sharing knowledge dan praktik langsung. Teknik pengumpulan data menggunakan lembar observasi. Hasil kegiatan menunjukkan adanya peningkatan pengetahuan dan kemampuan peserta tentang konsep dan penerapan hypnoparenting dalam pengasuhan anak usia dini. Hal itu ditunjukkan dengan hasil evaluasi kegiatan yang dilakukan, dimana terdapat sebanyak 21 orang peserta atau sebesar $80,77 \%$ yang berada pada kategori baik dan sangat baik.
\end{abstract}

Kata kunci: Anak, Hypnoparenting, Pengasuhan

\section{Abstract}

The pattern of proper parenting from parents will have a significant influence on children's development in the future. This service activity was entitled Training on the Application of Hypnoparenting in Early Childhood Care. This activity was carried out in Koya Barat, Jayapura Municipality, Papua Province. The purpose of this activity is to improve the understanding and ability of parents of children about the concept and application of hypnoparenting in early childhood care. The methods used in this activity are training, sharing knowledge and direct practice. Data collection techniques using observation sheets. The results of the activity indicated an increase in the knowledge and abilities of participants regarding the concept and application of hypnoparenting in early childhood care. This is indicated by the results of the evaluation of the activities carried out, where there were 21 participants or $80.77 \%$ who were in the good and very good categories.

Key words: Children, Hypnoparenting, Parenting

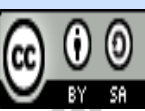

Received: 13 Februari, 2021

Revised: 25 Mei 2021

Available Online: 28 Mei 2021 


\section{Pendahuluan}

Pendidikan yang dilaksanakan pada usia dini merupakan dasar dari perkembangan seorang individu. Anak usia dini berada pada rentangan usia 0-8 tahun. Jika pada tahap ini, potensi anak tidak distimulasi secara tepat, maka anak akan berpotensi mengalami hambatan pada perkembangan selanjutnya. Sebaliknya, jika pada tahap ini stimulasi diberikan secara tepat maka akan memberikan dukungan positif terhadap perkembangan anak selanjutnya. Stimulasi terhadap perkembangan anak bukan hanya menjadi tanggung jawab guru, melainkan merupakan tanggung jawab bersama antara orang tua, guru, dan masyarakat. Oleh karenanya, stimulasi yang diberikan oleh oorang tua harus tepat sesuai tahapan perkembangan anak agar kelak perkembangannya dapat berjalan tanpa hambatan yang berarti. Stimulasi yang dimaksud diberikan oleh orang tua melalui pola pengasuhan yang tepat. (Purnama \& Hidayati, 2020) mengemukakan bahwa pengasuhan (parenting) merupakan segala tindakan yang harus dilakukan oleh orang tua anak dalam upaya mengembangkan aspek-aspek perkembangan anak. Selanjutnya (Pertiwi, 2014) mendefinisikan bahwa pola pengasuhan merupakan upaya untuk memberikan perhatian dan perlindungan kepada anak pada masa perkembangannya.

Adapun menurut (Dewanggi, Hastuti, \& Hernawati, 2012), pengasuhan merupakan usaha konkrit yang dilakukan oleh orang tua dengan tujuan untuk mempersiapkan anak agar dapat berkembang (kuat) dalam menghadapi berbagai tantangan. Dengan mengetahui cara pengasuhan yang tepat, maka orang tua akan memberikan manfaat yang berarti terhadap perkembangan anak sehingga tidak kehilangan momen pentingnya (Widiasari \& Pujiati, 2017). Menurut (Rakhmawati, 2015), pola pengasuhan yang tepat harus sejalan dengan standar nilai dan norma yang berlaku serta dapat menciptakan rasa nyaman bagi anak. Terbentuknya kepribadian seorang anak tidak terlepas dari bentuk pola asuh yang diberikan oleh orang tuanya (Ayun, 2017). Adanya support dari orang tua akan meningkatkan kepercayaan diri pada anak tersebut (Vani, Raharjo, \& Hidayat, 2015).

Berdasarkan hasil analisis situasi yang dilakukan oleh pengabdi, diperoleh fakta bahwa masih banyak orang tua anak yang tidak memahami cara pengasuhan yang tepat bagi anaknya (belum pernah mendapatkan pelatihan hypnoparenting) sehingga mereka berperilaku kasar, marah, atau bahkan ada yang sering memukul anaknya. Kondisi ini menyebabkan anak menjadi pemarah, malas belajar, pemalu, tidak percaya diri, sering mengeluarkan kata-kata tidak senonoh, dan lain sebagainya. Kondisi seperti ini tidak ideal untuk perkembangan anak, sebab jika hal tersebut dibiarkan, maka kondisi tersebut di atas lambat laun akan menjadi kepribadian anak. (Zahara, 2015) mengemukakan bahwa cara pengasuhan yang tepat adalah dengan tidak berlaku kasar baik secara fisik maupun psikis, tidak marah-marah serta tidak membiasakan untuk memukul anak. Oleh karenanya dalam mengasuh anak, tentunya memerlukan suatu metode yang dapat mendukung penanaman hal-hal positif kepada anak. (Damsid et al., 2020) mengemukakan bahwa untuk mengembangkan anak agar menjadi SDM yang berkualitas, maka diperlukan suatu persiapan dan perlakuan yang tepat sesuai dengan kondisi anak. Metode alternatif yang bisadigunakan dalam pengasuhan anak adalah hypnoparenting.

Hal ini sejalan dengan pendapat (Astuti, Widayati, \& Isfaizah, 2019) yang mengatakan bahwa hypnoparenting adalah salah satu metode yang dapat digunakan untuk mengarahkan anak sesuai harapan tanpa melakukan ancaman, dan kekerasan. Menurut (Tirtoni, 2018), Hypnoparenting merupakan cara mengasuh dan mendidik anak melalui pengaplikasian metode hipnosis. Menurut (Anugraheni, 2017b), hypnoparenting merupakan suatu teknik pola asuh yang dapat digunakan untuk mendisiplinkan anak melalui sugesti alam bawah sadar. Sejalan dengan pendapat di atas, (Silawati \& Yanti, 2015) menyatakan bahwa hypnoparenting merupakan salah satu cara dalam mendidik anak dengan menanamkan sugesti-sugesti positif sesuai dengan harapan orang tua. Lebih lanjut, (Ulfa, 2019) mendefinisikan hypnoparenting sebagai tidakan yang dilaksanakan untuk mempengaruhi cara berpikir anak sehingga dapat menunjukkan perbuatan baik dengan mempengaruhi alam bawah sadarnya.

Berdasarkan pendapat di atas, diperoleh kesimpulan bahwa hypnoparenting adalah cara atau metode pola asuh yang dilakukan dengan memberikan sugesti positif ke dalam alam bawah sadar anak untuk dapat mengubah perilakunya. Kualitas komunikasi antara orang tua dengan anak dapat 
ditingkatkan melalui hypnoparenting (Anugraheni, 2017a). Hal ini sesuai dengan pendapat (Astuti, Sofiyanti, \& Setyowati, 2019) yang mengatakan bahwa hypnoparenting merupakan teknik yang sangat bermanfaat untuk meningkatkan kecerdasan spiritual dan kualitas komunikasi orang tua dan anaknya. (Anggraini, 2018) menambahkan bahwa hypnoparenting dapat meningkatkan tingkat relaksasi seseorang. Hypnoparenting bertujuan untuk memberi kemudahan kepada orang tua dalam memberikan arahan (pembinaan) kepada anakanya tanpa adanya paksaan. (Siahaan, 2018). Penerapan hypnoparenting dilakukan dengan memanfaatkan gelombang theta pada otak anak (Wulansari, 2017).

Oleh karena itu, dalam penerapannya, diperlukan suatu persiapan yang matang, agar sugesti yang diberikan dapat masuk pada alam bawah sadar anak (Maghfiroh, 2015). Dengan dasar yang tersebut di atas, pengabdi melaksanakan kegiatan yang berjudul "Pelatihan Hypnoparenting dalam Pengasuhan Anak usia Dini". Tujuan kegiatan ini adalah untuk meningkatkan pemahaman dan kemampuan peserta (orang tua anak) tentang konsep dan penerapan hypnoparenting dalam pengasuhan yang dilaksanakan.

\section{Metode Pelaksanaan}

Kegiatan pengabdian kepada masyarakat ini dilaksanakan di Koya Barat, Kotamadya Jayapura, Provinsi Papua. Peserta dalam kegiatan ini adalah orang tua anak usia dini yang berjumlah 26 orang yang ditetapkan berdasarkan saran/masukan dari ketua Gugus Muara Tami Kotamadya Jayapura setelah melakukan evaluasi terhadap sikap dan perilaku anak di Sekolah.

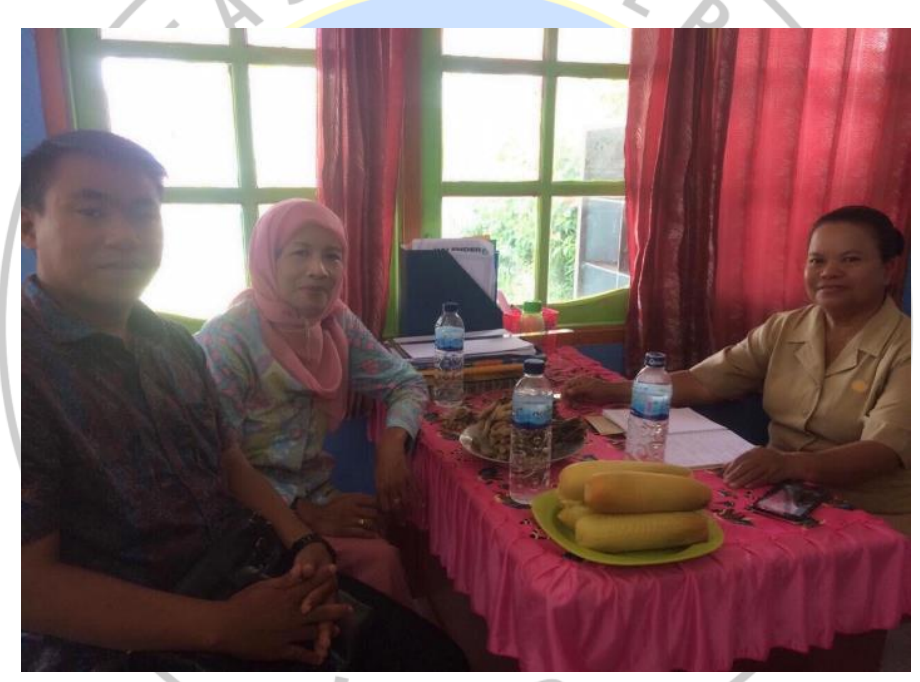

Gambar 1. Diskusi Penetapan Peserta dan Persiapan Pengabdian Kepada Masyarakat

Metode yang diterapkan pada kegiatan ini adalah training, sharing knowledge dan praktik langsung. Teknik pengumpulan data menggunakan lembar observasi. Data yang telah didapatkan dianalisis dengan menghitung perolehan skor dari setiap peserta kemudian dimasukkan ke dalam tabel frekuensi. Kriteria keberhasilan yang ditetapkan adalah minimal $80 \%$ dari peserta berada pada kriteria penilaian minimal baik.

\section{Hasil dan Pembahasan}

\subsection{Pelaksanaan Kegiatan}

Kegiatan ini dilaksanakan dalam bentuk pelatihan. Kegiatan dibuka langsung oleh ketua Gugus Muara Tami Kotamadya Jayapura. 


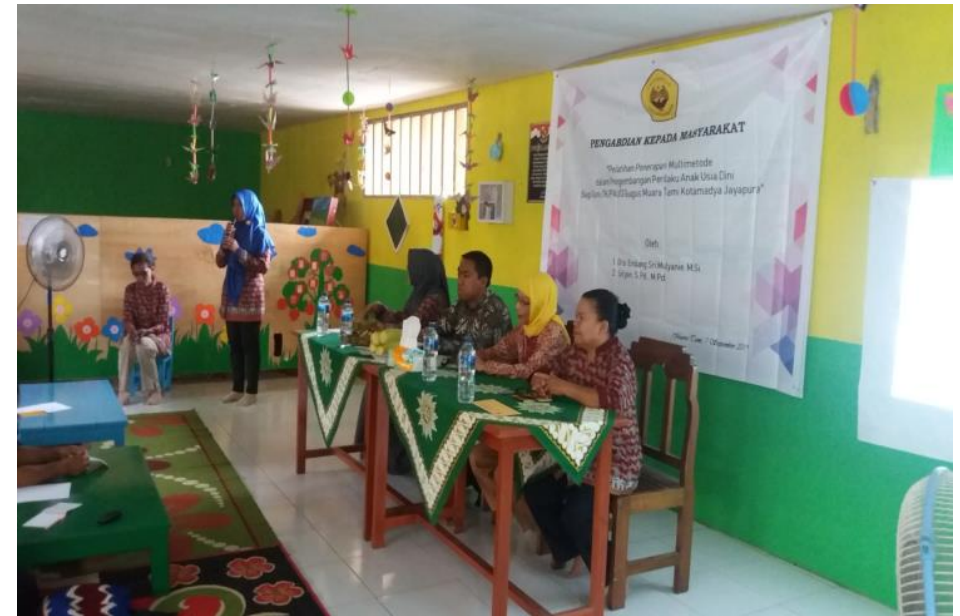

Gambar 2. Pembukaan Kegiatan Pengabdian Kepada Masyarakat

Setelah melaksanakan pembukaan, dilanjutkan dengan pemaparan materi dalam 2 sesi, kemudian dilanjutnya dengan praktek langsung pada sesi ke-3. Materi yang dipaparkan pada sesi pertama adalah tentang gelombang otak manusia.

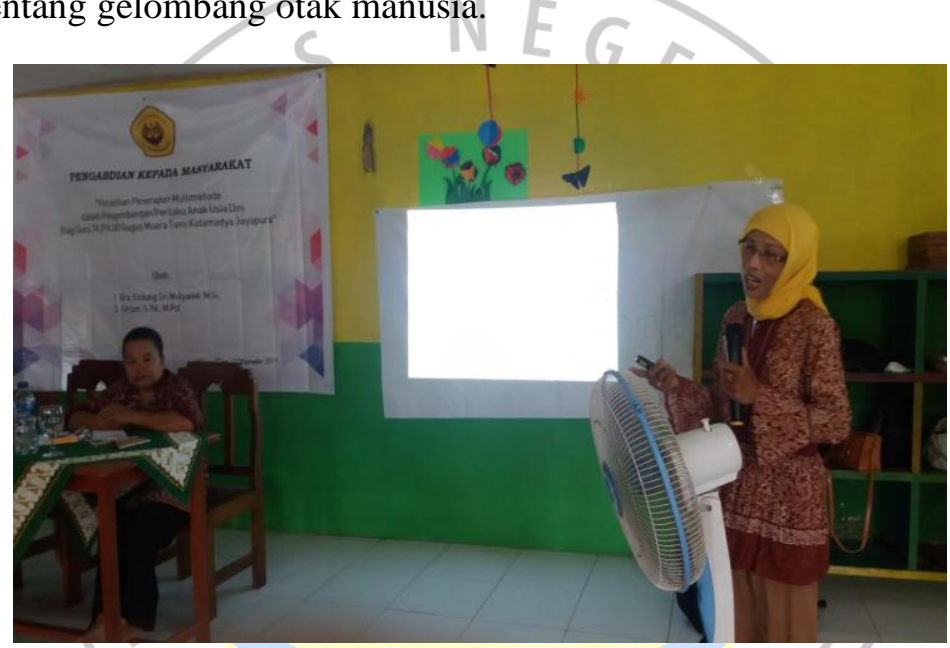

\section{Gambar 3. Pemaparan Materi Pertama Oleh Tim Pengabdi}

Setelah pemaparan materi pertama selesai, dilanjutkan dengan pemaparan materi kedua yaitu tentang pengenalan hypnoparenting dan dilanjutkan dengan praktek langsung.

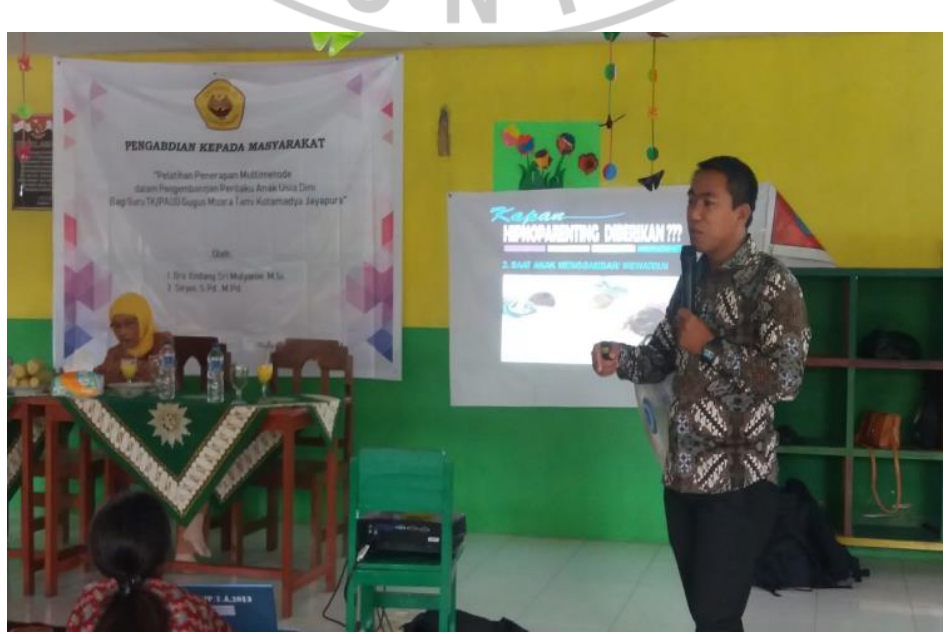

Gambar 4. Pemaparan Materi Kedua Oleh Tim Pengabdi 
Kegiatan kemudian diakhiri dengan foto bersama antara tim pengabdi dengan peserta.

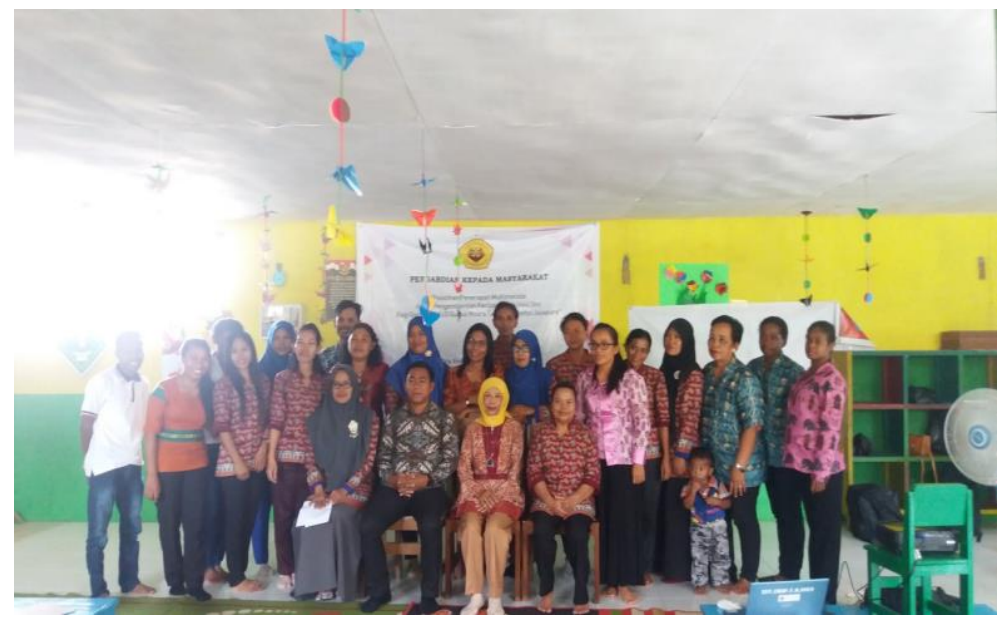

Gambar 5. Foto Bersama

\subsection{Hasil Kegiatan}

Berdasarkan hasil kegiatan pengabdian kepada masyarakat yang telah dilaksanakan, maka dapat diuraikan hasil sebagai berikut:

Tabel 1. Hasil Kegiatan Pengabdian Kepada Masyarakat

\begin{tabular}{lcc}
\hline Kriteria Penilaian & Frekuensi & Persentase (\%) \\
\hline Sangat baik & 8 & 30,77 \\
\hline Baik & 13 & 50 \\
\hline Cukup Baik & 5 & 19,23 \\
\hline Kurang Baik & 0 & 0 \\
\hline Sangat tidak baik & 0 & 0 \\
\hline Jumlah & $\mathbf{2 6}$ & $\mathbf{1 0 0}$ \\
\hline
\end{tabular}

Hasil pada tabel di atas menunjukkan bahwa terdapat 5 orang tua yang berada pada kriteria penilaian cukup baik, terdapat 13 orang yang berada pada kriteria baik, serta terdapat 8 orang yang berada pada kriteria sangat baik. Adapun kriteria kurang baik dan sangat tidak baik menunjukkan angka 0 yang berarti tidak ada orang tua yang berada pada kriteria penilaian tersebut. Merujuk pada hasil di atas serta kriteria keberhasilan kegiatan yang ditetapkan yaitu minimal $75 \%$ peserta berada pada kriteria penilaian minimal baik, maka dapat disimpulkan bahwa kegiatan pengabdian kepada masyarakat ini berhasil dengan baik dengan perolehan total $80,77 \%$ peserta yang berada pada kategori baik dan sangat baik.

\subsection{Faktor Pendukung dan Penghambat}

Faktor yang menjadi pendukung terlaksananya kegiatan pengabdian ini adalah adanya dukungan dari pimpinan pengabdi, antusiasme peserta yang sangat tinggi, serta adanya kerjasama dan dukungan yang sangat baik dari ketua Gugus Muara Tami Kotamadya Jayapura. Adapun faktor penghambat antara lain susahnya jaringan komunikasi di tempat tinggal peserta, serta kondisi sosial politik di Papua yang kurang kondusif menjelang kegiatan pengabdian dilaksankan (aksi penolakan rasisme).

\subsection{Khalayak Sasaran}

Khalayak sasaran dalam kegiatan pengabdian kepada masyarakat ini adalah orang tua anak usia dini yang direkomendasikan oleh ketua Gugus Muara Tami Kotamadya Jayapura. 


\section{Kesimpulan}

Merujuk pada tujuan pelaksanaan kegiatan pengabdian kepada masyarakat ini, maka dapat disimpulkan bahwa terjadi peningkatan pengetahuan dan kemampuan peserta terhadap konsep dan penerapan hypnoparenting dalam pengasuhan anak usia dini. Hal tersebut dapat dilihat dari hasil evaluasi kegiatan yang dilakukan, dimana telah terdapat sebanyak $80,77 \%$ peserta yang berada pada kategori baik dan sangat baik. Hasil ini telah melampaui kriteria keberhasilan yang telah ditetapkan.

\section{Daftar Pustaka}

Anggraini, S. (2018). Hypnoparenting Effects Towards Fatigue As An Impact Of Chemotherapy Among Pediatric Patients With Acute Lymphoblastic Leukemia. Jurnal Keperawatan Indonesia, 21(2), 77-83. http://doi.org/10.7454/jki.v21i2.570

Anugraheni, I. (2017a). Hypnoparenting Terhadap Temper Tantrum Pada Anak Prasekolah di TK Islam Terpadu Bina Insani Kecamatan Mojoroto Kota Kediri. Dunia Keperawatan, 5(1), 2125. http://doi.org/http://dx.doi.org/10.20527/dk.v5i1.3637

Anugraheni, I. (2017b). Pengaruh Hypnoparenting Terhadap Kejadian Picky Eater Pada Anak Prasekolah di TK Islam Terpadu Bina Insani Kecamatan Mojoroto Kota Kediri. Jurnal Kesehtan Hesti Wira Sakti, 5(1), 24-29.

Astuti, F. P., Sofiyanti, I., \& Setyowati, H. (2019). Penerapan Hypnoparenting Untuk Mengatasi Permasalahan Pada Anak Usia Dini. Jurnal Pengabdian Masyarakat Kebidanan, 1(2), 1523.

Astuti, F. P., Widayati, \& Isfaizah. (2019). Pengaruh Hypnoparenting Terhadap Penurunan Enuresispada Anak Usia Prasekolah. Jurnal SIKLUS, 08(01), 8-14. http://doi.org/http://dx.doi.org/10.30591/siklus.v8i1.1050

Ayun, Q. (2017). Pola Asuh Orang Tua Dan Metode Pengasuhan Dalam Membentuk Kepribadian Anak. ThufuLA: Jurnal Inovasi Pendidikan Guru Raudhatul Athfal, 5(1), 103-122. http://doi.org/http://dx.doi.org/10.21043/thufula.v5i1.2421

Damsid, H., Roslan, S., Sarpin, Hos, J., Arsyad, M. (2020). Pelatihan Parenting Bagi Keluarga Dalam Meningkatkan Dan Mendukung Perkembangan Fisik, Emosional, Sosial, Finansial, Dan Intelektual Anak Di Wilyah Pesisir Pantai Nirwana Di Kelurahan Sulaa, Kecamatan Betoambari, Kota Baubau. Jurnal Anoa, 1(1), 28-35. http://doi.org/http://dx.doi.org/ 10.1234/anoa.v1i01.10822

Dewanggi, M., Hastuti, D., \& Hernawati, N. (2012). Pengasuhan Orang Tua Dan Kemandirian Anak Usia 3-5 Tahun Berdasarkan Gender Di Kampung Adat Urug. Jurnal Ilmu Keluarga Dan Konsumen, 5(1), 20-28. http://doi.org/https://doi.org/10.24156/jikk.2012.5.1.19

Maghfiroh, A. (2015). Implementasi Hypnoparenting Dalam Pembentukan Kedisiplinan Anak Di Taman Kanak-Kanak Pangulir Budi I Kerangkulon, Kecamatan Wonosalam, Kabupaten Demak. Tesis. Universitas Negeri Semarang.

Pertiwi, S. (2014). Pola Pengasuhan Untuk Mengembangkan Karakter Anak (Studi Kasus Di Yayasan Tunas Rajawali Kota Semarang). Journal of Non Formal Education and Community Empowerment, 3(1), 17-29. http://doi.org/https://doi.org/10.24156/jikk. 2012.5.1.19

Purnama, S., \& Hidayati, L. (2020). Pengasuhan Anak Usia Dini dalam Hikayat Indraputra. Jurnal Obsesi, 4(2), 520-542. http://doi.org/10.31004/obsesi.v4i2.391

Rakhmawati, I. (2015). Peran Keluarga dalam Pengasuhan Anak. KONSELING RELIGI: Jurnal Bimbingan Konseling Islam, 6(1), 1-18. http://doi.org/http://dx.doi.org/10.21043/ kr.v6i1.1037

Siahaan, M. B. (2018). Pengaruh Pola Asuh Berbasis Hypnoparenting Dan Penyuluhan Status Gizi Pada Ibu Terhadap Peningkatan Pengetahuan Ibu Dan Status Gizi Anak Balita Di Klinik Sumiariani Medan Johor Tahun 2018. Laporan. Politeknik Kesehatan Kemenkes RI.

Silawati, \& Yanti, A. (2015). Pemanfaatan Hypnoparenting dalam Menanamkan Karakter Anak di Lembaga Konseling dan Konsultasi Pekanbaru. Jurnal RISALAH, 26(2), 77-85. http://doi.org/http://dx.doi.org/10.24014/jdr.v26i2.1216 
Tirtoni, F. (2018). Pelatihan Parenting Skill "Hypnoparenting Sebagai Teknik dalam Memberikan Motifasi Belajar Kepada Anak Guna Melatih Kemandirian Anak Sejak Dini. Jurnal Pengabdian Kepada Masyarakat (Abdimas), 1(1), 35-44.

Ulfa, R. A. (2019). Hypnoparenting; Sebuah Metode Menjinakkan Alligator's Brains Pada Anak Usia Dini. SCAFFOLDING: Jurnal Pendidikan Islam Dan Multikulturalisme, 1(2), 39-49. http://doi.org/https://doi.org/10.37680/scaffolding.v1i2.118

Vani, G. C., Raharjo, S. T., \& Hidayat, E. N. (2015). Pengasuhan (Good Parenting) Bagi Anak Dengan Disabilitas. In N. Nurwati, N. Mulyana, B. M. Taftazani, N. C. Apsari, \& M. B. Santoso (Eds.), Prosiding Penelitian \& Pengabdian Masyarakat (pp. 96-102). Bandung: FISIP Universitas Padjajaran. http://doi.org/https://doi.org/10.24198/jppm.v2i1

Widiasari, Y., \& Pujiati, D. (2017). Pengasuhan Anak Usia Dini Bagi Orang Tua Pekerja. Jurnal Indria, 2(2), 68-77. http://doi.org/http://dx.doi.org/10.24269/jin.v2n2.2017.pp68-77

Wulansari, B. Y. (2017). Pendidikan Gender Sejak Usia Dini Melalui Hypnoparenting. Jurnal Indria, 2(2).

Zahara, R. A. (2015). Hypnoparenting dalam Pendidikan Islam. Jurnal Tribakti, 26(1), 20-43. http://doi.org/https://ejournal.iai-tribakti.ac.id/index.php/tribakti/article/view/200

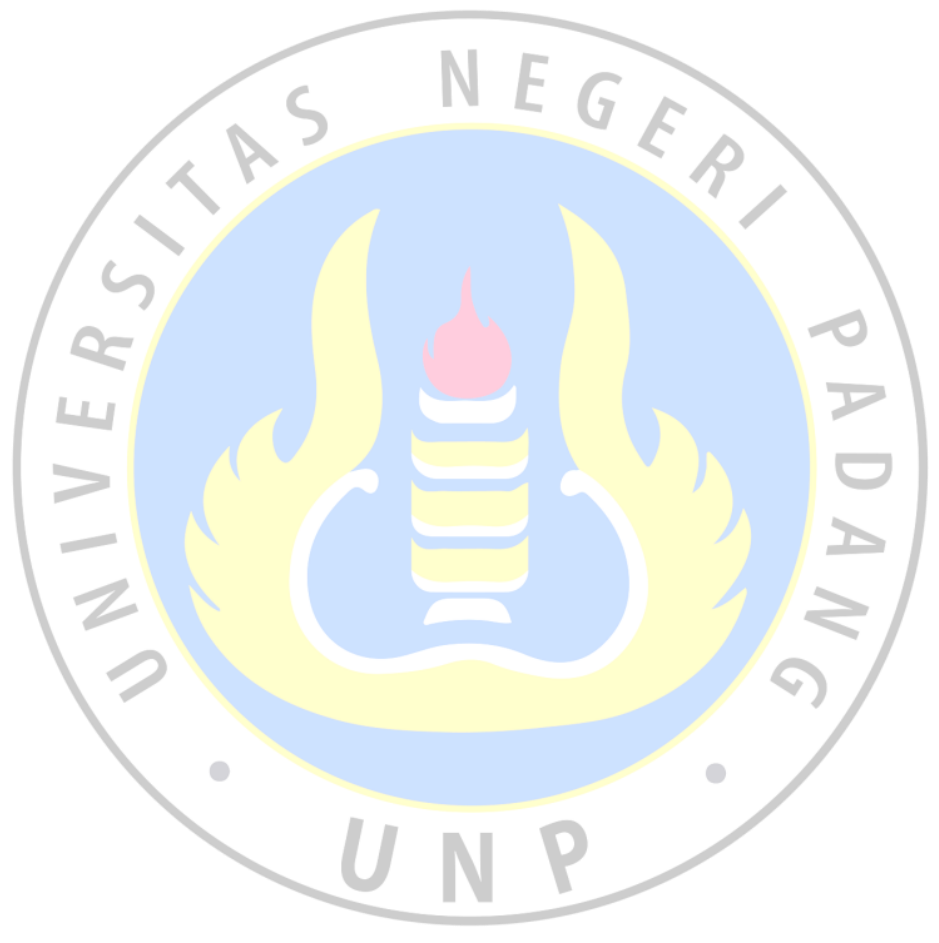

